\title{
Acute renal failure due to non-traumatic rhabdomyolysis
}

\author{
K. S. CHUGH \\ M.D., M.A.M.S., F.I.C.A. \\ I. V. S. NATH \\ M.D., D.M., M.A.M.S. \\ P. C. Singhal \\ M.D., D.M. \\ S. K. PAREeK \\ M.D. \\ H. S. UBROI \\ M.D. \\ A. K. SARKAR \\ M.Sc., Ph.D. \\ Departments of Nephrology and Biochemistry, Postgraduate Institute of Medical Education and \\ Research, Chandigarh 160012, India
}

\begin{abstract}
Summary
Seventeen patients with acute renal failure of diverse aetiology showed myoglobinuria and elevated levels of serum creatine phosphokinase (mean 119.2 Sigma u./ml) and adolase (mean 88.5 Sibley-Lehninger (SL) $\mathrm{u} . / \mathrm{ml}$ ), indicating the presence of diffuse muscle cell injury. The primary conditions which led to rhabdomyolysis and acute renal failure were burns, eclampsia, prolonged labour, crush injury, epileptiform convulsions, status asthmaticus, viral myositis and intoxication with chemicals including copper sulphate, mercuric chloride and zinc phosphide. In 10 non-myoglobinuric patients with acute renal failure, serum creatine phosphokinase was normal (mean 8.9 Sigma $u . / \mathrm{ml}$ ) and serum aldolase was only slightly elevated (mean 11.2 SL u./ml). Although uric acid was elevated in both groups, the values were significantly higher in myoglobinuric (mean 0.728 $\pm 0.199 \mathrm{mmol} / \mathrm{l}$ ) compared to non-myoglobinuric patients (mean $0.583 \pm 0.093 \mathrm{mmol} / \mathrm{l})$. During the oliguric phase, hypocalcaemia was observed in $82.2 \%$ of myoglobinuric patients and in $20 \%$ of non-myoglobinuric patients. Ten out of 15 patients with myoglobinuric renal failure developed hypercalcaemia during the diuretic phase whereas only 3 non-myoglobinuric patients showed a transient hypercalcaemia. Although the mean serum potassium was somewhat higher in the myoglobinuric patients, the difference between the 2 groups was not significant. It is concluded that acute renal failure associated with non-traumatic rhabdomyolysis is not infrequent and may occur in a variety of conditions where gross evidence of muscle injury is lacking.
\end{abstract}

\section{Introduction}

The pathogenetic role of traumatic rhabdomyolysis and myoglobinuria in acute renal failure due to crush injury was first recognized by Bywaters and
Beall (1941) during World War II. Since then, an increasing number of conditions leading to myoglobinuric renal failure have been identified where evidence of muscle injury was present without any history of direct mucle trauma (Vertel and Knochel, 1967; Schrier, Henderson and Tischer, 1967. Jackson, 1970; Grossman et al., 1974; Kofflep Friedler and Massry, 1976; Singhal, Chugh an Gulati, 1978). This study documents the presence्द of non-traumatic rhabdomyolysis in some of the hitherto unreported conditions and brings out the significant differences in the biochemical parameters of patients with myoglobinuric and nonmyoglobinuric renal failure.

\section{Material and methods}

Twenty-seven patients with established acute renal failure who were referred to the Artificial Kidney Unit of the Institute of Medical Education and Research, Chandigarh, for dialysis, were studied. These included 17 patients in whom preliminary screening revealed positive evidence of myoglobinuria and 10 non-myoglobinuric patients, to serve as controls.

The diagnosis of acute renal failure was established on the basis of a history of oliguria/anuria of more than $48 \mathrm{hr}$ in most patients, all of whom were in a previously healthy, progressive elevation of blood urea and serum creatinine, a urinary sodium concentration of more than $40 \mathrm{mmol} / \mathrm{l}$ of sodium and low urinary osmolality.

Specific investigations relevant to rhabdomyolysis included urinalysis for evidence of myoglobin (Glauser, Wagner and Glauser, 1972), estimates of serum creatine phosphokinase, serum aldolase (Sibley and Lehninger's method) and serial levels of 
serum potassium, uric acid and calcium by standard techniques. Besides these, relevant haematological, radiological and bacteriological investigations were carried out in all the patients.

\section{Results}

On the basis of positive or negative evidence of urinary myoglobin, patients were divided into 2 groups: myoglobinuric and non-myoglobinuric.

\section{Myoglobinuric patients}

There were 17 patients in this group, 8 male and 9 female (Table 1). Their ages ranged from 17 to 50 years with a mean age of 27.8 years. Fifteen patients were oliguric at the time of admission and 2 (cases 2 and 6) were non-oliguric. The duration of oliguria varied from 2 to 30 days with a mean of 9 days. Urinary output in 2 non-oliguric patients ranged from 700 to $900 \mathrm{ml} /$ day. Dark brown colouration of the urine had been observed by 7 patients.

Predisposing factors. The predisposing factors which had contributed to the development of rhabdomyolysis and acute renal failure in this group are shown in Table 1. These include 2 patients each with extensive burns, eclampsia, prolonged labour, and copper sulphate intoxication and one patient each with crush injury, intracerebral haemorrhage with epileptiform convulsions, malignant hypertension, temporal lobe epilepsy, grand mal epilepsy, zinc phosphide poisoning, viral myositis, mercuric chloride poisoning and status asthmaticus.

Four patients (cases 2, 4, 5 and 15) were admitted in a state of coma of 48-72 $\mathrm{hr}$ duration. Cases 1 and 6 who suffered from 70 to $80 \%$ burns showed evidence of gross heat injury to muscles. Case 10 was admitted in an exhaustive state from status asthmaticus for over 3 days. One patient with eclampsia (case 4) and one with prolonged labour (case 14) delivered macerated fetuses. Case 2 showed a marked degree of hypotonia and absence of deep tendon reflexes at the time of admission.

Additional factors contributing to renal failure. Apart from rhabdomyolysis, additional factors which could have contributed to the development of acute renal failure have also been summarized in

TABLE 1. Factors contributing to the development of rhabdomyolysis and renal failure

\begin{tabular}{|c|c|c|c|c|}
\hline Case & Age Sex & Precipitating events & $\begin{array}{l}\text { Contributing factors to } \\
\text { rhabdomyolysis }\end{array}$ & $\begin{array}{l}\text { Additional factors contributing to } \\
\text { development of renal failure }\end{array}$ \\
\hline 1 & $35 \mathrm{M}$ & Burns (Electrical) & Heat injury & Fluid and electrolytic depletion \\
\hline 2 & $32 \mathrm{M}$ & Malignant hypertension & Coma, hypokalaemia & - \\
\hline 3 & $40 \mathrm{M}$ & Crush injury & Direct muscle injury & Hypotension \\
\hline 4 & $30 \mathrm{~F}$ & Eclampsia & Convulsions, coma, macerated fetus & - \\
\hline 5 & $30 \mathrm{M}$ & Intracerebral haemorrhage & Convulsions, coma & - \\
\hline 6 & $45 \mathrm{M}$ & Burns (flame) & Heat injury & $\begin{array}{l}\text { Fluid and electrolyte loss, } \\
\text { hypotension }\end{array}$ \\
\hline 7 & $20 \mathrm{~F}$ & Epilepsy (temporal) & Convulsions & Gastroenteritis, dehydration \\
\hline 8 & $50 \mathrm{~F}$ & Copper sulphate poisoning & Direct myotoxicity & $\begin{array}{l}\text { Gastrointestinal bleed, } \\
\text { intravascular haemolysis }\end{array}$ \\
\hline 9 & $22 \mathrm{~F}$ & Copper sulphate poisoning & Direct myotoxicity & $\begin{array}{l}\text { Gastrointestinal bleed, } \\
\text { intravascular haemolysis }\end{array}$ \\
\hline 10 & $25 \mathrm{M}$ & Status asthmaticus & Muscular exertion & Dehydration \\
\hline 11 & $22 \mathrm{M}$ & Mercuric chloride poisoning & Direct myotoxicity & Gastrointestinal bleed, fluid loss \\
\hline 12 & $25 \mathrm{~F}$ & Prolonged labour & Muscular exertion & Dehydration \\
\hline 13 & $30 \mathrm{~F}$ & Viral myositis & Muscle damage & Dehydration, hypotension \\
\hline 14 & $30 \mathrm{~F}$ & Prolonged labour & Muscular exertion, macerated fetus & Accidental haemorrhage \\
\hline 15 & $20 \mathrm{~F}$ & Zinc phosphide poisoning & Coma, direct myotoxicity & Vomiting, dehydration \\
\hline 16 & $30 \mathrm{M}$ & Epilepsy (grand mal) & Convulsions & - \\
\hline 17 & $17 \mathrm{~F}$ & Eclampsia & Convulsions & - \\
\hline
\end{tabular}


Table 1. Ten patients (cases 1, 6-13 and 15) had evidence of moderate to severe dehydration at the time of admission. Three patients (cases 3,6 and 13) had hypotensive shock; 2 of them required the administration of 6-10 litres of fluid and one patient with crush injury received 4 units of blood. Two patients with copper sulphate intoxication (cases 8 and 9) and one with mercuric chloride poisoning (case 11) had a history of massive gastrointestinal bleeding before admission. Both patients with copper sulphate intoxication, in addition, showed evidence of intravascular haemolysis.

Urinalysis. During the oliguric phase, urinary osmolality ranged between 280 and 319 mosmol $/ \mathrm{kg}$ with a mean of $290 \mathrm{mosmol} / \mathrm{kg}$ and urinary sodium varied between 60 and $90 \mathrm{mmol} / \mathrm{l}$ with a mean of $74 \mathrm{mmol} / \mathrm{l}$. During the diuretic phase, the urinary osmolality ranged between 290 and 427 mosmol/kg with mean of $366 \mathrm{mosmol} / \mathrm{kg}$ and urinary sodium between 70 and $120 \mathrm{mmol} / \mathrm{l}$ with a mean of 84 $\mathrm{mmol} / \mathrm{l}$.

Blood biochemistry. The blood urea ranged from 13 to $65 \mathrm{mmol} / \mathrm{l}($ mean $38 \pm 15)$ and serum creatinine from 424 to $1432 \mu \mathrm{mol} / \mathrm{l}$ (mean $893 \pm 328$, Table 2 ). Peak levels of serum potassium before submitting the patients to dialysis ranged from 4.4 to $7 \cdot 2$ $\mathrm{mmol} / \mathrm{l}$ with a mean of $5 \cdot 2 \pm 1 \cdot 2 \mathrm{mmol} / \mathrm{l}$ (except case 2 who presented with a non-oliguric renal failure). Seven patients (cases 1, 3, 6, 9, 10, 11 and 17) were observed to have developed biochemical evidence of hyperkalaemia ( $>5.5 \mathrm{mmol} / \mathrm{l})$ during the early phase of oliguria.

Uric acid levels were elevated in all and ranged from 0.5 to $1.1 \mathrm{mmol} / 1$ (mean $0 \cdot 7 \pm 0 \cdot 2$ ). Serum calcium ranged between 1.95 and $2.87 \mathrm{mmol} / 1$ (mean $2 \cdot 19 \pm 0.25$ ) during the oliguric phase and 1.87 to $3.25 \mathrm{mmol} / 1$ (mean $2 \cdot 80 \pm 0 \cdot 37$ ) during the diuretic phase. Ten patients (cases 3, 4, 5, 7, 10, 11, 12, 13, 16 and 17) had hypercalcaemia during the diuretic phase.

Significant elevation of the serum creatine phosphokinase and aldolase were observed in all patients, serum creatine phosphokinase levels ranging between 42 and 298 Sigma u./ml (mean $119 \pm 74)$ and serum aldolase between 38 and 192 SL u./ml (mean $88 \pm 37$ ).

Renal histology. Renal biopsy tissue was available for histology in 10 patients. The histological appearances were consistent with acute tubular necrosis in all the cases.

Course. Five patients died and 12 recovered. The cause of death in 2 patients with burns (cases 1 and 6) was extensive tissue necrosis with superadded septicaemia. One patient (case 5) died during the

TABLe 2. Peak serum biochemical levels in patients with myglobinuric renal failure

\begin{tabular}{|c|c|c|c|c|c|c|c|c|}
\hline \multirow[b]{3}{*}{ Case } & \multirow[b]{3}{*}{$\begin{array}{c}\text { Urea } \\
(\mathrm{mmol} / \mathrm{l})\end{array}$} & \multirow[b]{3}{*}{$\begin{array}{c}\text { Creatinine } \\
(\mu \mathrm{mol} / \mathrm{l})\end{array}$} & \multirow[b]{3}{*}{$\begin{array}{l}\text { Potassium } \\
(\mathrm{mmol} / \mathrm{l})\end{array}$} & \multirow[b]{3}{*}{$\begin{array}{l}\text { Uric acid } \\
(\mathrm{mmol} / \mathrm{l})\end{array}$} & \multirow{3}{*}{$\begin{array}{c}\text { Creatine } \\
\text { phosphokinase } \\
\text { Sigma } \\
\text { u./ml }\end{array}$} & \multirow{3}{*}{$\begin{array}{c}\text { Aldolase } \\
\text { SL } \\
u . / m l\end{array}$} & \multicolumn{2}{|c|}{ Calcium } \\
\hline & & & & & & & \multicolumn{2}{|c|}{$(\mathrm{mmol} / \mathrm{l})$} \\
\hline & & & & & & & $\begin{array}{c}\text { Oliguric } \\
\text { phase }\end{array}$ & $\begin{array}{c}\text { Diuretic } \\
\text { phase }\end{array}$ \\
\hline 1 & 16 & 424 & 6.0 & 0.9 & 84 & 80 & $2 \cdot 12$ & + \\
\hline 2 & 26 & 451 & $1 \cdot 5$ & 0.8 & 70 & 60 & $*$ & 1.87 \\
\hline 3 & 55 & 1432 & $5 \cdot 8$ & 0.7 & 125 & 100 & 1.95 & $3 \cdot 12$ \\
\hline 4 & 50 & 972 & $4 \cdot 8$ & 1.0 & 70 & 80 & $2 \cdot 12$ & $3 \cdot 25$ \\
\hline 5 & 13 & 663 & $4 \cdot 5$ & 0.6 & 84 & 80 & 1.97 & 3.0 \\
\hline 6 & 16 & 539 & $6 \cdot 6$ & $1 \cdot 1$ & 75 & 70 & $2 \cdot 2$ & + \\
\hline 7 & 41 & 1255 & $5 \cdot 4$ & 0.7 & 175 & 114 & $2 \cdot 05$ & $3 \cdot 0$ \\
\hline 8 & 65 & 663 & $4 \cdot 5$ & 0.5 & 298 & 43 & $*$ & 2.62 \\
\hline 9 & 45 & 1370 & $6 \cdot 2$ & 0.6 & 125 & 75 & $2 \cdot 12$ & $2 \cdot 62$ \\
\hline 10 & 37 & 972 & $5 \cdot 6$ & 0.5 & 90 & 75 & $2 \cdot 2$ & $3 \cdot 12$ \\
\hline 11 & 58 & 1326 & $7 \cdot 0$ & 0.7 & 126 & 84 & $2 \cdot 17$ & 3.0 \\
\hline 12 & 46 & 1238 & $5 \cdot 2$ & 1.0 & 70 & 75 & 2.05 & $3 \cdot 25$ \\
\hline 13 & 33 & 628 & $5 \cdot 4$ & 0.5 & 42 & 192 & $2 \cdot 87$ & $2 \cdot 75$ \\
\hline 14 & 43 & 769 & $5 \cdot 1$ & 0.7 & 180 & 80 & $2 \cdot 15$ & $2 \cdot 5$ \\
\hline 15 & 31 & 884 & $4 \cdot 4$ & 0.9 & 93.5 & 38 & $2 \cdot 32$ & $2 \cdot 37$ \\
\hline 16 & 33 & 822 & $5 \cdot 1$ & 05 & 274 & 130 & $2 \cdot 0$ & $2 \cdot 7$ \\
\hline 17 & 45 & 778 & $5 \cdot 6$ & 0.5 & 45 & 129 & $2 \cdot 6$ & $2 \cdot 75$ \\
\hline Mean & 39 & 893 & $5 \cdot 2$ & 0.7 & 119 & 89 & $2 \cdot 19 \ddagger$ & $2 \cdot 8 \ddagger$ \\
\hline s.d. & 15 & 328 & $1 \cdot 2$ & 0.2 & 74 & 37 & 0.25 & 0.37 \\
\hline Normal values & $2 \cdot 5-6 \cdot 5$ & $60-120$ & $3 \cdot 8-5 \cdot 0$ & $0 \cdot 1-0.4$ & $0-12$ & $2-8$ & $2 \cdot 1-2 \cdot 6$ & $2 \cdot 1-2 \cdot 6$ \\
\hline
\end{tabular}

* These patients were non-oliguric.

$\dagger$ Died before passing into diuretic phase.

$\ddagger$ The difference was statistically significant $(P<0.001)$. 
diuretic phase from cerebral oedema and tentorial herniation. Another patient (case 8) suffering from copper sulphate intoxication recovered completely from renal failure but continued to have gastrointestinal bleeding resulting in circulatory collapse and death. Post-mortem revealed massive grangrene of the gut in this case. The cause of death in one patient with malignant hypertension and coma could not be ascertained.

\section{Non-myoglobinuric renal failure}

This group comprises 10 patients, 3 male and 7 female. Their ages ranged from 25 to 40 years. All were oliguric at the time of admission and the duration of oliguria from 7 to 21 days (mean 10 days).

Predisposing factors. Obstetrical incidents were responsible for the acute renal failure in 3 patients (post-partum bleeding in 2 and septic abortion in one), fluid and electrolyte depletion due to severe diarrhoea and dehydration in one, drug-induced intravascular haemolysis in 3 patients, snake bite in one and viral hepatitis in one.

Urinalysis. Urine was negative for myoglobin in all these patients. The urinary osmolality during the oliguric phase ranged between 269 and 393 mosmol $/ \mathrm{kg}$ (mean 310.2 mosmol $/ \mathrm{kg}$ ) and urinary sodium between 40 and $115 \mathrm{mmol} / \mathrm{l}$ (mean 80 $\mathrm{mmol} / \mathrm{l})$. During the diuretic phase, the urinary osmolality varied from 304 to $410 \mathrm{mosmol} / \mathrm{kg}$ (mean $357 \mathrm{mosmol} / \mathrm{kg}$ ) and urinary sodium concentration ranged between $70-108 \mathrm{mmol} / \mathrm{l}$ with a mean of $94 \mathrm{mmol} / \mathrm{l}$. The difference in the urinary osmolality and sodium concentration between the non-myoglobinuric and myoglobinuric patients was not significant $(P>0.05)$.
Blood biochemistry. The blood urea ranged from 23 to $55 \mathrm{mmol} / \mathrm{l}$ (mean $39 \pm 12$ ) and serum creatinine from 619 to $1344 \mu \mathrm{mol} / \mathrm{l}$ (mean $844 \pm 216$ ). Serum potassium varied from $4 \cdot 1$ to $6.0 \mathrm{mmol} / \mathrm{l}$ (mean $4.9 \pm 0.6)$ and uric acid from 0.4 to $0.7 \mathrm{mmol} / 1$ (mean $0 \cdot 6 \pm 0 \cdot 10$ ). Serum calcium ranged between 1.87 and $2.87 \mathrm{mmol} / 1$ (mean $2.37 \pm 0.28$ ) during the oliguric phase and between 2.0 and $3.25 \mathrm{mmol} / 1$ (mean $2.47 \pm 0.45$ ) during the diuretic phase. Three patients (cases 2, 6 and 7) showed higher values of serum calcium during the diuretic phase (Table 3 ).

The serum creatine phosphokinase ranged from 5 to 13 Sigma $\mathrm{u} . / \mathrm{ml}$ (mean $9 \pm 3$ ) and serum aldolase ranged between 4 and 22 SL u. (mean $11 \pm 6$ ).

Renal histology. Renal tissue was studied in 6 patients. Histological features revealed changes consistent with acute tubular necrosis in 4 , patchy cortical necrosis in one and diffuse cortical necrosis in one.

Course. Nine patients recovered and one died (case 9). The cause of death in the latter case was brorichopneumonia and pulmonary oedema.

Myoglobinuric versus non-myoglobinuric renal failure

There was no apparent difference in the duration of oliguria or severity of renal failure between myoglobinuric and non-myoglobinuric patients. However, statistical evaluation revealed significant difference in the peak levels of serum creatine phosphokinase $(P<0.001)$, serum aldolase $(P<$ $0.001)$ and uric acid $(P<0.025)$ levels between the 2 groups. Although the mean serum potassium was higher in the myoglobinuric patients, the difference was not significant $(P>0 \cdot 05)$. No significant difference was found between the mean levels of blood urea and creatinine in the 2 groups $(P>0.05)$. Whereas the difference between the serum calcium levels in the oliguric and diuretic

TABLE 3. Peak serum biochemical levels in patients of non-myoglobinuric renal failure

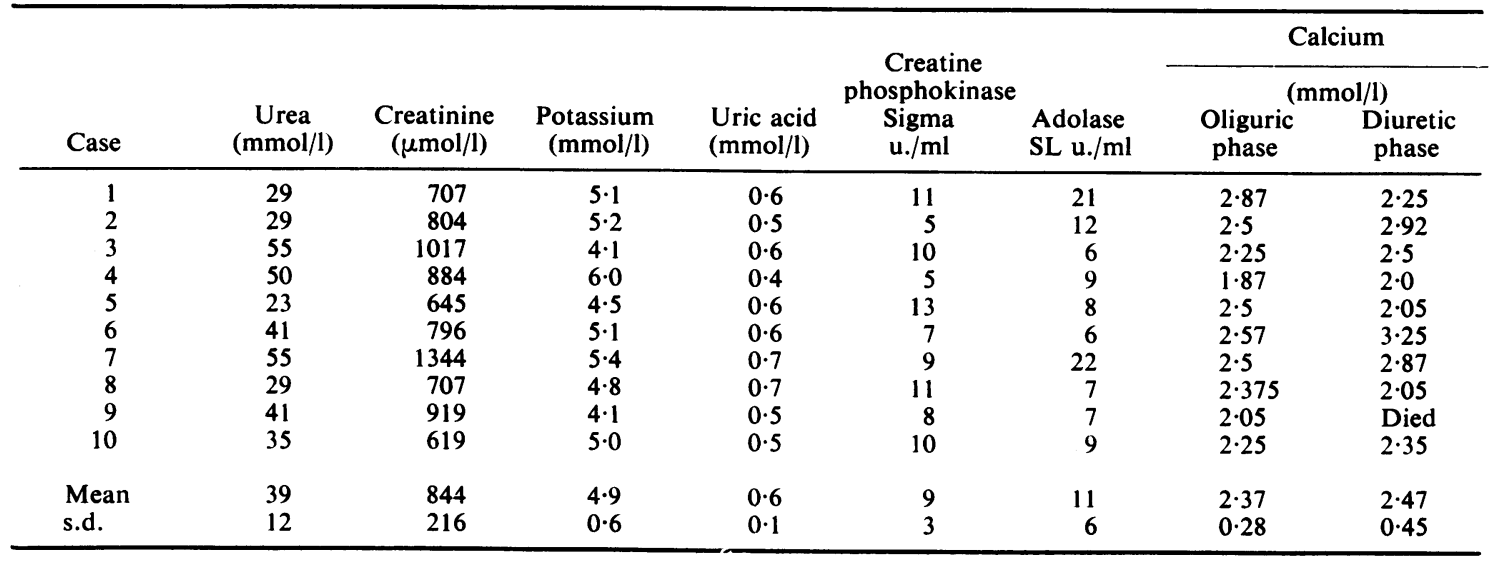

Normal values - see Table 2 . 
phase was statistically significant in the myoglobinuric patients $(P<0.001)$ this difference was not significant in the non-myoglobinuric group $(P>0.05)$.

\section{Discussion}

The presence of myoglobin in the urine and elevation of the serum creatine phosphokinase and aldolase activities are regarded as characteristic features of rhabdomyolysis. The application of these criteria have enabled recognition of the pathogenetic role of muscle cell injury in many patients with acute renal failure in whom gross clinical evidence of muscle necrosis is absent. Recent studies have shown that rhabdomyolysis may be a major factor in the causation of acute renal failure in $5-7 \%$ of patients (Grossman et al., 1974; Koffler et al., 1976). Perhaps the condition is more common than has been recognized so far. The aetiological factors which have been reported as causing rhabdomyolysis and acute renal failure include crush injury (Bywaters and Beall, 1941), severe muscular exertion (Jackson, 1970), hyperpyrexia (Schrier, Henderson and Tischer, 1967), carbon monoxide poisoning (Mautner, 1955), electroshock therapy (Selzer, Reinhart and Deeney, 1963), use of diamorphine (Klock and Sexton, 1973), diabetic ketoacidosis (Grossman et al., 1974), drugs coma (Penn, Rowland and Fraser, 1972), viral myositis (Grossman et al., 1974), convulsions (Hamilton et al., 1972; Singhal, Chugh and Gulati, 1978) and hypokalaemia (Van Horn, Drori and Schwartz, 1970). In the present study acute renal failure associated with nontraumatic rhabdomyolysis was observed in patients with burns, eclampsia, prolonged labour, copper sulphate, mercuric chloride and zinc phosphide poisoning, convulsive seizures due to various causes, viral myositis and status asthmaticus. Traumatic rhabdomyolysis due to crush injury led to acute renal failure in one patient. Although over 500 patients with acute renal failure have been dialysed in this unit over a 13-year period including several cases with similar settings (Chugh et al., 1975, 1976, 1977a,b, 1978), the exact incidence cannot be assessed since the earlier cases were not investigated on these lines.

In the myoglobinuric group, $82.2 \%$ patients showed hypocalcaemia during the oliguric phase and hypercalcaemia was observed in $66.6 \%$ of the patients in this study during the diuretic phase. Hypocalcaemia during oliguric phase and hypercalcaemia during diuretic phase have been regarded as characteristic findings in patients with acute renal failure following rhabdomyolysis (Meroney 1957; Tavill et al., 1964; Segal, Miller and Moses, 1968; Grossman and Lange, 1968; Fortner, 1971). The mechanism underlying these findings is not entirely clear. Hypocalcaemia has been attributed to release of phosphate compounds from damaged muscles into the extra-cellular fluid leading to hyperphosphataemia which in turn facilitates deposition of calcium phosphate in the damaged muscles. This latter has been demonstrated radiologically (Clark and Sumerling, 1966) as well as in the muscle biopsy tissue (Mautner, 1955; Grunfeld et al., 1972). During the diuretic phase, excessive renal excretion of phosphate leads to liberation of previously deposited salts from the damaged muscles, thus inducing a phase of hypercalcaemia. In 2 reported cases (Leonard and Eichner, 1970; Wu et al., 1972) significant elevation of the parathyroid hormone levels were observed. However, the role of parathyroid hormone in the induction of hypercalcaemia has not been clearly defined and requires further studies.

Though hyperuricaemia was observed in all the 17 patients in the myoglobinuric group, markedly elevated levels which were out of proportion to the severity of the renal failure $(>1.0 \mathrm{mmol} / \mathrm{l})$ were recorded in only 3 patients. Knochel, Dotin and Hamburger (1974) have recorded over-production of uric acid associated with muscle injury following strenuous exercise in a hot environment. This is likely to be due to enhanced release of purine precursors into the circulation which in turn are metao bolized to uric acid in the liver.

Hyperkalaemia in the early phase of renal failure is generally observed in patients who have a hyper catabolic state or rhabdomyolysis. In uncomplicated cases, hyperkalaemia usually occurs after prolonged oliguria. In a co-operative study, the rate of rise of serum potassium was found to be $0.25 \mathrm{mmol} / 1$ per $24 \mathrm{hr}$ for all patients with acute failure versus 0.64 $\mathrm{mmol} / \mathrm{l}$ for those who had sustained muscle injuries (Bluemle, Webster and Elkinton, 1959). Rapid increments of the serum potassium in patients with rhabdomyolysis is possibly related to release of intracellular potassium into the extra-cellular fluid. However, no significant difference was observed in the serum potassium levels in the myoglobinuric compared to non-myoglobinuric patients in the present study.

Severe muscular exertion due to repeated convulsions, status asthmaticus and prolonged labour probably contributed to the development of rhabdomyolysis in 8 patients of the present series. Muscular exercise has been reported to be associated with increased activity of SGPT, SGOT, lactic acid dehydrogenase and creatine phosphokinase (CPK). Both in human subjects as well as in experimental animals, rises in the activity of these enzymes was higher following a given quantity of exercise in the unconditioned state than after training (Fowler et al., 1962; Garbus, Highman and Altland, 1964; Fowler, Gardner and Kazerunian, 1968). 
Myoglobinuria following acute copper intoxication has been reported earlier in one isolated instance (Klein, Metz and Price, 1972). As the patient reported by these authors had remained in coma for a prolonged period, both coma and copper intoxication could have contributed to the development of rhabdomyolysis. Two patients with coppersulphate poisoning in the present study showed rhabdomyolysis. Muscle-cell injury and rhabdomyolysis in these 2 patients may have been due to the direct cytotoxic effect of copper.

Prolonged coma and immobilization in one position have been incriminated as important factors for the development of muscle cell injury (Penn et al., 1972). Myoglobinuria in this situation has been considered either due to direct compression of the muscle or partial occlusion of the regional vascular supply because of the weight of the body. Four of the present patients had remained comatosed for more than $\mathbf{4 8} \mathrm{hr}$. Coma is likely to have been the major contributory factor for induction of rhabdomyolysis in these cases.

Potassium deficiency has been reported to be associated with elevated activity of lactic dehydrogenase, SGOT and CPK, both in man (Craig and Jacobius, 1967; Van Horn et al., 1970) and in experimental animals (Knochel and Schlein, 1972). Animals with advanced potassium deficiency have been observed to have a subnormal muscle membrane potential suggesting loss of integrity of the muscle cell membranes (Bilbrey, Carter and Knochel, 1973). In the present series, severe hypokalaemia was considered to be a major contributory factor for massive muscle cell injury in one patient. This patient had developed a severe degree of hypokalaemia $(1.5 \mathrm{mmol} / \mathrm{l})$ owing to inappropriate use of chlorothiazide without adequate supplementation of potassium salts and because of the associated secondary hyperaldosteronism which is a well known feature of malignant hypertension.

The exact mechanism by which myoglobinuria induces acute renal failure is not well understood. The various postulated mechanisms include obstruction of the tubular lumina by myoglobin casts (Jaenike, 1976), back diffusion of glomerular filtrate through breached tubular epithelium (Bank, Mutz and Aynedijian, 1967) and diminished glomerular filtration rate (Oken, Arce and Wilson, 1966). Dehydration is known to facilitate the induction of acute renal failure in animal experiments (Oken, 1972). A significant degree of dehydration could have played a contributory role in 10 patients in the present series. However, cases have been reported where acute renal failure developed in the absence of obvious dehydration (Grossman et al., 1974).

The mortality amongst the myoglobinuric patients was $29.3 \%$. The overall mortality amongst patients with acute renal failure due to all causes has been reported to vary from 40 to $60 \%$ (Leading Article, 1973; Chugh et al., 1978). It has been reported to be significantly lower in patients of non-traumatic rhabdomyolysis (Grossman et al., 1974) and higher in patients with traumatic rhabdomyolysis and acute renal failure.

\section{References}

Bank, N., Mutz, B.F., AynediJian, H.S. (1967) The role of leakage of tubular fluid in anuria due to mercury poisoning. Journal of Clinical Investigation, 46, 695.

Bilbrey, G.L., Carter, N.W. \& Knochel, J.P. (1973) Skeletal muscle resting membrane potential in potassium deficiency. Journal of Clinical Investigation, 52, 3011.

Bluemle, L.W., Webster, G.D. \& Elkinton, J.R. (1959) Acute tubular necrosis: Analysis of one hundred cases with respect to mortality, complications and treatment with and without dialysis. Archives of Internal Medicine, 104, 180.

Bywaters, E.G.L. \& Beall, D. (1941) Crush injuries with impairment of renal function. British Medical Journal, 1, 427.

Chugh, K.S., Aikat, B.K., Sharma, B.K., Dash, S.C., MatheW, M.T. \& DAS, K.C. (1975) Acute renal failure following snake bite. American Journal of Tropical Medicine and Hygiene, 24, 692.

Chugh, K.S., Sharma, B.K., Singhal, P.C., Das, K.C. \& DatTA, B.N. (1977a) Acute renal failure following copper sulphate intoxication. Postgraduate Medical Journal, 53, 18.

Chugh, K.S., Singhal, P.C., Nath, I.V.S., Tewari, S.C., Methusethupathy, M.A., Pal, Y., UberoI, H.S., Vishwanathan, S. \& Sharma, L. (1978) Spectrum of acute renal failure in North India. Journal of Association of Physicians of India, 29, 112.

Chugh, K.S., Singhal, P.C., Sharma, B.K., Mahakur, A.C., Pal, Y., Datta, B.N. \& Das, K.C. (1977b) Acute renal failure due to intravascular hemolysis in the North Indian patients. American Journal of the Medical Sciences, 274, 139.

Chugh, K.S., Singhal, P.C., Sharma, B.K., Pal, Y., Mathew, M.T., Dhall, K. \& Datta, B.N. (1976) Acute renal failure of obstetric origin. Obstetrics and Gynecology, 48, 642.

Clark, J.G. \& Sumerling, M.D. (1966) Muscle necrosis and calcification in acute renal failure due to barbiturate intoxication. British Medical Journal, 2, 274.

FORTNER, R.W. (1971) Acute renal insufficiency in heat stress injury. (Abstract.) American Society of Nephrology, $5,23$.

Fowler, W.M., Chowdhary, S.R., Pearson, C.M., GardNER, G. \& BRATTON, R. (1962) Changes in serum enzyme levels after exercise in trained and untrained subjects. Journal of Applied Physiology, 17, 943.

Fowler, W.M., Gardner, G.W. \& Kazerunian, H.H. (1968) The effect of exercise on serum enzymes. Archives of Physical Medicine and Rehabilitation, 49, 554.

Garbus, J., Highman, B. \& Altland, P.D. (1964) Serum enzymes and lactic dehydrogenase isoenzymes after exercise and training in rats. American Journal of Physiology, 207, 467.

Glauser, S.C., Wagner, H. \& Glauser, E.M. (1972) A rapid simple, accurate test for differentiating hemoglobinuria from myoglobinuria. American Journal of the Medical Sciences, 264, 135. 
Graig, F.A. \& JACobius, F.M. (1967) Elevated serum enzyme levels associated with hypokelemia, abstracted. Annals of Internal Medicine, 66, 1059.

Grossman, H.H. \& LANGE, H. (1968) Hypercalcemia during the diuretic phase of acute renal failure. Annals of Internal Medicine, 68, 1066.

Grossman, R.A., Hamilton, R.W., Morse, B.M., Penn, A.S. \& GoldberG, M. (1974) Non-traumatic rhabdomyolysis and acute renal failure. New England Journal of Medicine, 291, 807.

Grunfeld, J.O., Ganeval, D., Chanard, J. et al. (1972) Acute renal failure in McArdle's disease; report of two cases. New England Journal of Medicine, 286, 1237.

Hamilton, R.W., Gardner, L.B., Penn, A.S. \& Goldberg, M. (1972) Acute tubular necrosis caused by exerciseinduced myoglobinuria. Annals of Internal Medicine, 77, 77.

JACKSON, R.C. (1970) Exercise-induced renal failure and muscle damage. Proceedings of the Royal Society of Medicine, 63, 566

JAENIKE, J.R. (1967) The renal lesion associated with haemoglobinuria: Study of pathogenesis of the excretory defect in the rat. Journal of Clinical Investigation, 46, 695.

Klein Jr, W.J., Metz, E.N. \& Price, A.R. (1972) Acute copper intoxication: hazard of hemodialysis. Archives of Internal Medicine, 129, 578.

Klock, J.C. \& Sexton, M.J. (1973) Rhabdomyolysis and acute myoglobinuric renal failure following heroin use. California Medicine, 119, 5.

KNOChel, J.P., Dotin, L.N. \& Hamburger, R.J. (1974) Heat stress and exercise and muscle injury: effects on urate metabolism and renal function. Annals of Internal Medicine, 81, 321.

KNOChel, J.P. \& Schlein, E.M. (1972) On the mechanism of rhabdomyolysis in potassium depletion. Journal of Clinical Investigation, 51, 1750.

Koffler, A., Friedler, R.M. \& Massry, S.G. (1976) Acute renal failure due to non-traumatic rhabdomyolysis. Annals of Internal Medicine, 85, 23.

LeADING ARTICLE (1973) Acute renal failure. Lancet, ii, 134.

LEONARD, C.D. \& EichneR, E.R. (1970) Acute renal failure and transient hypercalcemia in idiopathic rhabdomyolysis. Journal of the American Medical Association, 211, 1539.
Mautner, L.S. (1955) Muscle necrosis associated with carbon monoxide poisoning. Archives of Pathology, 60, 136.

Meroney, W.H. (1957) The acute calcification of traumatized muscle with particular reference to acute post-traumatic $C$ renal insufficiency. Journal of Clinical Investigation, 36, 825.

OKEN, D.E. (1972) Modern concepts of the role of nephrotoxic agents in the pathogenesis of acute renal failure Progress in Biochemistry and Pharmacology, 7, 219.

OKen, D.E., ARCE, M.L. \& WiLson, D.R. (1966) Glycerolinduced hemoglobinuric acute renal failure in the rat. $I$. Micropuncture study of development of oliguria. Journal of Clinical Investigation, 45, 724.

PenN, A.S., Rowland, L.P. \& Fraser. D.W. (1972) Drugs coma and myoglobinuria. Archives of Neurology, 26, 336.

SChrier, R.W., Henderson, H.S. \& Tischer, C.C. (1967) Nephropathy associated with heat stress and exercise. Annals of Internal Medicine, 67, 356.

Segal, A.J., Miller, M. \& Moses, A.M. (1968) Hypercalcemia during the diuretic phase of acute renal failure. Annals of Internal Medicine, 68, 1066.

Selzer, M.L., Reinhart, M.J. \& Deeney, J.M. (1963) Acute renal failure following EST. American Journal of Psychiatry. 120, 602.

Singhal, P.C., Chugh, K.S. \& Gulati, D.R. (1978) Myoglobinuria and renal failure after status epilepticus. Neurology, 28, 200.

Tavill, A.S., Evanson, J.M., Baker, S.B. \& Hewitt, V. (1964) Idiopathic paroxysmal myoglobinuria with acute renal failure and hypercalcemia. New England Journal of Medicine, 271, 283.

VAN Horn, G., Drori, J.B. \& Schwartz, F.D. (197@ Hypokalemic myopathy and elevation of serum enzymes . Archives of Neurology, 22, 335.

VERTEL, R.M.\& KNOCHEL, J.P. (1967) Acute renal failure duet to heat injury: an analysis of cases associated with a high incidence of myoglobinuria.

Wu, B.C., Pillay, V.K.G., Hawkar, C.B., Arbruste, K.F.W., ShaPIRo, H.S. \& ING, T.S. (1972) Hypercalcemia in acute renal failure of acute alcoholic rhabdomyolysis. South African Medical Journal, 46, 1631. 